\title{
Meta-analysis of risk factors for CCLNM in patients with unilateral cNO PTC
}

\author{
Wei Sun, Boyuan Zheng, Zhihong Wang, Wenwu Dong, Yuan Qin and Hao Zhang \\ Department of Thyroid Surgery, The First Hospital of China Medical University, Shenyang, Liaoning Province, China
}

Correspondence should be addressed to H Zhang: haozhang@cmu.edu.cn

\section{Summary}

Background: In patients with papillary thyroid cancer (PTC) with clinical negative central lymph nodes ( $\mathrm{CNO}$ ), the use of prophylactic central lymph node dissection remains controversial. Contralateral central lymph node metastasis (CCLNM) occurs in $3.88-30.63 \%$ of patients with cNO PTC. Therefore, the present meta-analysis aimed to obtain evidence for CCLNM risk factors in unilateral CNO PTC.

Materials and methods: Relevant studies were identified in the PubMed, SCIE, and Wanfang databases up to Oct 31, 2019. The included patients had undergone lobectomy or total thyroidectomy with bilateral central lymph node dissection and were diagnosed pathologically with PTC. Revman 5.3 software was applied for statistical analysis.

Results: Thirteen studies comprising 2449 patients were included. The factors associated with increased CCLNM risk in patients with cN0 disease were: age $<45$ years (odds ratio $(O R)=1.89,95 \% \mathrm{Cl}=1.43-2.49, P<0.00001)$, male sex $(\mathrm{OR}=1.67,95 \% \mathrm{Cl}=1.24-2.24$, $P=0.0007)$, extrathyroidal extension $(\mathrm{OR}=1.63 ; 95 \% \mathrm{Cl}=1.17-2.28 ; P=0.004)$, tumor size $\geq 1 \mathrm{~cm}(\mathrm{OR}=2.63,95 \% \mathrm{Cl} 1.85-3.74, P<0.00001)$, lymphovascular invasion $(\mathrm{OR}=4.27$, $95 \% \mathrm{Cl}=2.47-7.37, P<0.00001)$, and ipsilateral central lymph node metastasis $(\mathrm{OR}=11.42,95 \% \mathrm{Cl}=5.25-24.86, P<0.00001)$. However, no association was found for capsular invasion, multifocality, or Hashimoto thyroiditis.

Conclusion: The meta-analysis identified that age $<45$ years, tumor $\geq 1 \mathrm{~cm}$, male sex, lymphovascular invasion, extrathyroidal extension, and ipsilateral central lymph node metastasis are related to CCLNM in patients with unilateral CNO PTC. These factors should influence the use of prophylactic central lymph node dissection in this group of patients.

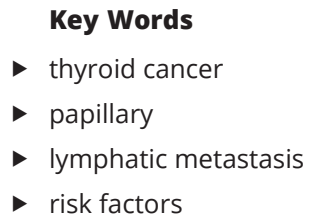

Endocrine Connections (2020) 9, 387-395

\section{Introduction}

The most prevalent endocrine malignancy is thyroid cancer, which accounts for $1 \%$ of all malignancies. Recently, morbidity caused by thyroid cancer has increased by three-fold $(1,2)$. Histologically, the most common type of thyroid cancer is papillary thyroid carcinoma (PTC), representing $>90 \%$ of all thyroid cancers (1). The prognosis of PTC is generally favorable and the overall prognosis is excellent. The 5-, 10-, and 20-year survival rates of PTC are 94,89 , and $87 \%$, respectively $(3,4)$. Patients with PTC develop cervical lymph node metastases in approximately $30-80 \%$ of cases $(5,6)$. However, in patients with PTC, the significance of lymph node metastasis is a matter of debate. For example, some studies reported that relapse is affected by lymph node metastasis, whereas survival is not (7). However, a recent large single-institution study showed that the outcome of PTC could be predicted using the ratio of the number of positive lymph nodes to the total number of excised nodes (8).

Therapeutic central neck dissection is acceptable in patients with clinically positive PTC. However, it remains controversial as to whether patients with clinically negative central lymph nodes (cNO) should receive prophylactic central lymph node dissection (PCLND). At present, there is no convincing evidence that patient

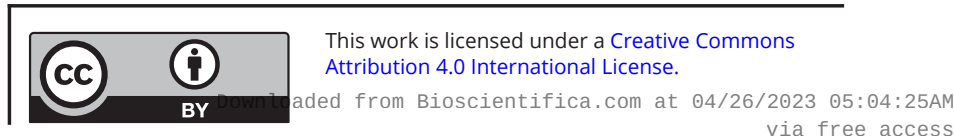


prognosis is improved using PCLND. Nixon et al. observed $100 \% 5$ - and 10-year disease-specific survival rates among patients with PTC who did not receive PCLND (9). In addition, dynamic observation of central lymph nodes is considered safe and should be performed for all patients with PTC before and during surgery to ensure that they are free from central neck metastasis (10). However, other studies have reported benefits of PCLND in patients with cNO. For example, PCLDN can help to accurately diagnose tumor-node-metastasis (TNM) staging, help decide on the use of thyroid-stimulating hormone (TSH) suppression therapy or radioactive iodine (RAI) therapy, and predict the possibility of lateral lymph node metastases $(11,12$, 13). Other studies have reported that PCLND can reduce thyroglobulin levels during postoperative follow-up, reduce postoperative recurrence, and improve diseasespecific survival $(14,15,16)$.

PTC initially spreads from the thyroid gland to lymph nodes in the pretrachea, the ipsilateral tracheoesophageal groove, and to nodes in the ipsilateral neck and mediastinum $(17,18)$. Contralateral central compartment and contralateral neck and skip metastases (negative central and positive lateral or mediastinal lymph nodes) are generally rare. However, in PTC, the frequency of central lymph node metastasis is high, leading to $3.88-30.63 \%$ of patients with unilateral cNO disease developing contralateral central lymph node metastasis (CCLNM) $(19,20)$. If bilateral PCLND was applied to all of the PTC patients, the rates of hypoparathyroidism and vocal cord palsy would inevitably increase $(21,22)$. To reveal central lymph node metastases, preoperative imaging such as contrast-enhanced CT and ultrasound (US) are used widely. However, both US and enhanced CT are not particularly accurate, showing sensitivities of $27.5-38 \%$ and $38.9-50 \%$, respectively $(23,24,25)$. Therefore, treatment options for contralateral central lymph node compartments should be considered carefully to balance the risks and benefits of PCLND. However, although risk factors have been identified for patients with cNO disease, the results were inconsistent, probably because of the small sample sizes used. Therefore, in the present study, a meta-analysis was used to assess the clinical features of CCLNM in patients with cNO PTC.

\section{Methods}

This meta-analysis was performed according to the guidelines of the preferred reporting items for systematic reviews and meta-analyses (PRISMA) statement (26).

\section{Search strategy}

The Wan Fang, Web of science, and PubMed databases were subjected to a comprehensive literature search for studies published up to Oct 31, 2019 using the key words ((()((((central) OR central compartment) OR level VI) OR paratracheal)) AND lymph node) AND contralateral)) AND ()(((()thyroid cancer) OR thyroid carcinoma) OR thyroid neoplasm)) AND papillary)) OR PTC). The two authors (Sun W and Zheng BY) independently completed the selection process. Differences were resolved via discussion

\section{Selection criteria}

The meta-analysis included studies that met these criteria: (a) Retrospective or prospective cohort studies; (b) the lesion was only located in one side of the thyroid lobe, and no nodule was found in the other side of the thyroid lobe; (c) only patients who underwent unilateral lobectomy or total thyroidectomy plus bilateral PCLND, and PTC was confirmed pathologically intraoperatively or postoperatively; (d) patients with PTC and clinically negative neck nodes; and (e) the medical records were complete to allow data extraction. The exclusion criteria comprised: (a) Patients with a history of other thyroid malignancies or previous treatment for head and neck cancer; (b) case reports, reviews, conference abstracts, letters to the editor, and so on; and (c) patients whose family has a history of thyroid cancer.

\section{Data extraction and quality assessment}

Two authors (Sun W and Zheng BY) extracted the data independently. Detailed information was recorded on first author, publication years, author country, study design, PTC/PTMC, case number, CCLNM rate, and surgical intervention. Independent records were made for nine possible risk factors of CCLNM and the corresponding numbers of patients. The nine risk factors comprised sex, age, tumor size, multifocality, extrathyroidal extension, capsular invasion, lymphovascular invasion, Hashimoto thyroiditis, and ipsilateral central lymph node metastasis. We included data on the number of CCLNMs. To assess the quality of the included studies, we used the NewcastleOttawa quality assessment scale.

\section{Statistical analysis}

Review Manager 5.3 (https://community.cochrane. org) was used to perform all the statistical analyses.

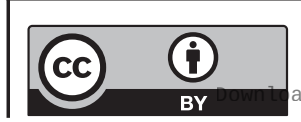

This work is licensed under a Creative Commons Attribution 4.0 International License. 
The results are presented as the odds ratios (ORs) with 95\% CIs. Unless otherwise specified, $P$ values $<0.05$ are considered statistically significant. In addition, the $I^{2}$ statistics and the $\mathrm{Q}$ test were used to quantify heterogeneity. When $I^{2}$ was less than $50 \%$ and $P$ was greater than 0.1 , a fixed effect model was used. In other cases, we used a random effect model. To test for possible publication bias, Begg's funnel plots were used.

\section{Results}

Database screening identified 521 studies, of which 130 were excluded because of repetition and language. Next, 361 studies were excluded after careful scanning of their titles and abstracts because they comprised case reports, reviews, and unrelated studies. Thirty articles remained for full text evaluation. After applying the inclusion criteria, the meta-analysis included 13 studies comprising 2449 patients, among which nine studies were retrospective and four studies were prospective. The basic characteristics of the articles are shown in Table 1. The Begg's funnel chart is provided in the Supplementary information (see section on supplementary materials given at the end of this article). Figure 1 shows a flowchart of the selection process.

\section{Age}

Heterogeneity was assessed using a fixed-effects model $\left(P=0.68, \quad I^{2}=0 \%\right)$. To analyze the association with age and CCLNM, 45 years old was used as the cut off. Among patients with cNO PTC, $16.15 \%$ of patients who were less than 45 years old and $7.99 \%$ of patients who were $\geq 45$ years old had CCLNM. Upon meta-analysis, these data showed that an increased rate of CCLNM was associated with age $<45$ years old in patients with cNO PTC $(\mathrm{OR}=1.89,95 \% \mathrm{CI}=1.43-2.49, P<0.00001)$ (Fig. $2 \mathrm{~A})$ (Supplementary Fig. 1).

Sex

Heterogeneity was assessed using a fixed-effects model $\left(P=0.77, I^{2}=0 \%\right)$. Among patients with cN0 PTC, $17.34 \%$ of men and $10.57 \%$ of women had CCLNM. Thus, male patients with cNO PTC had a significantly higher incidence of CCLNM than female patients $(\mathrm{OR}=1.67,95 \% \mathrm{CI}=$ 1.24-2.24, $P<0.00001$ ) (Fig. 2B) (Supplementary Fig. 2).

\section{Tumor size}

Seven studies were included in the analysis of the influence of tumor size in patients with PTC. A fixed-effects model was used in this analysis $\left(P=0.19, I^{2}=32 \%\right)$. The incidence of CCLNM was $18.21 \%$ in patients with a tumor size $\geq 1 \mathrm{~cm}$ and $7.59 \%$ in patients with a tumor size $<1 \mathrm{~cm}$. Thus, CCLNM was associated significantly with tumor size $\geq 1 \mathrm{~cm}$ in patients with cNO PTC (OR=2.63, 95\% $\mathrm{CI}=1.85-3.74, P<0.00001$ ) (Fig. 2C) (Supplementary Fig. 3).

\section{Multifocality}

Nine articles, including 1926 patients, were included in the relationship between CCLNM and multifocality in the unilateral lobe. Meta-analysis with a fixed effect model was used $\left(P=0.27, I^{2}=20 \%\right)$. The results showed that there was no statistically significant difference in the rate of CCLNM between the patients with multifocality and single focality $(\mathrm{OR}=1.00,95 \% \mathrm{CI}=0.61-1.63 ; P=1.00)$ (Fig. 3A) (Supplementary Fig. 4).

Table 1 Basic characteristics of the included studies.

\begin{tabular}{|c|c|c|c|c|c|c|c|c|}
\hline Author & Year & Country & Study design & PTC/PTMC & $\begin{array}{c}\text { Case } \\
\text { number }\end{array}$ & $\begin{array}{l}\text { Contralateral } \\
\text { metastasis }\end{array}$ & Operation & $\begin{array}{c}\text { Quality } \\
\text { assessment }\end{array}$ \\
\hline Ahn BH (29) & 2014 & Korea & prospective & PTC & 368 & $7.10 \%$ & TT + bilateral CLND & 8 \\
\hline Chen Q (46) & 2015 & China & retrospective & PTC & 218 & $13.30 \%$ & TT + bilateral CLND & 7 \\
\hline Eun YG (47) & 2014 & Korea & retrospective & PTC & 140 & $10.00 \%$ & TT + bilateral CLND & 8 \\
\hline Gu Z (50) & 2016 & China & retrospective & PTC & 46 & $21.74 \%$ & TT/lobectomy + bilateral CLND & 6 \\
\hline He W (51) & 2017 & China & retrospective & PTC & 149 & $23.49 \%$ & TT + bilateral CLND & 7 \\
\hline Ji YB (19) & 2016 & Korea & retrospective & PTC & 361 & $3.88 \%$ & TT + bilateral CLND & 7 \\
\hline Koo BS (20) & 2009 & Korea & prospective & PTC & 111 & $30.63 \%$ & TT + bilateral CLND & 8 \\
\hline Lim YC (48) & 2009 & Korea & retrospective & PTMC & 86 & $10.47 \%$ & TT + bilateral CLND & 7 \\
\hline Miao SS (49) & 2014 & China & prospective & PTC & 184 & $16.30 \%$ & TT + bilateral CLND & 6 \\
\hline Qin A (52) & 2017 & China & retrospective & PTC/PTMC & 245 & $15.10 \%$ & TT + bilateral CLND & 7 \\
\hline Roh JL (6) & 2015 & Korea & prospective & PTC & 184 & $9.78 \%$ & TT + bilateral CLND & 8 \\
\hline Yoo HS (53) & 2017 & Korea & retrospective & PTC & 215 & $4.19 \%$ & TT + bilateral CLND & 7 \\
\hline Zhang L (54) & 2016 & China & retrospective & PTC & 169 & $14.20 \%$ & TT + bilateral CLND & 7 \\
\hline $\begin{array}{l}\text { https://ec.biosci } \\
\text { https://doi.org/1 }\end{array}$ & ica.co & -0058 & Publis & $\begin{array}{l}\text { (c) } 2020 \text { The a } \\
\text { led by Bioscientif }\end{array}$ & $\begin{array}{l}\text { thors } \\
\text { ca Ltd }\end{array}$ & & $\begin{array}{l}\text { This work is licensed under a Creat } \\
\text { Attribution } 4.0 \text { International Licens }\end{array}$ & ve Commons \\
\hline
\end{tabular}




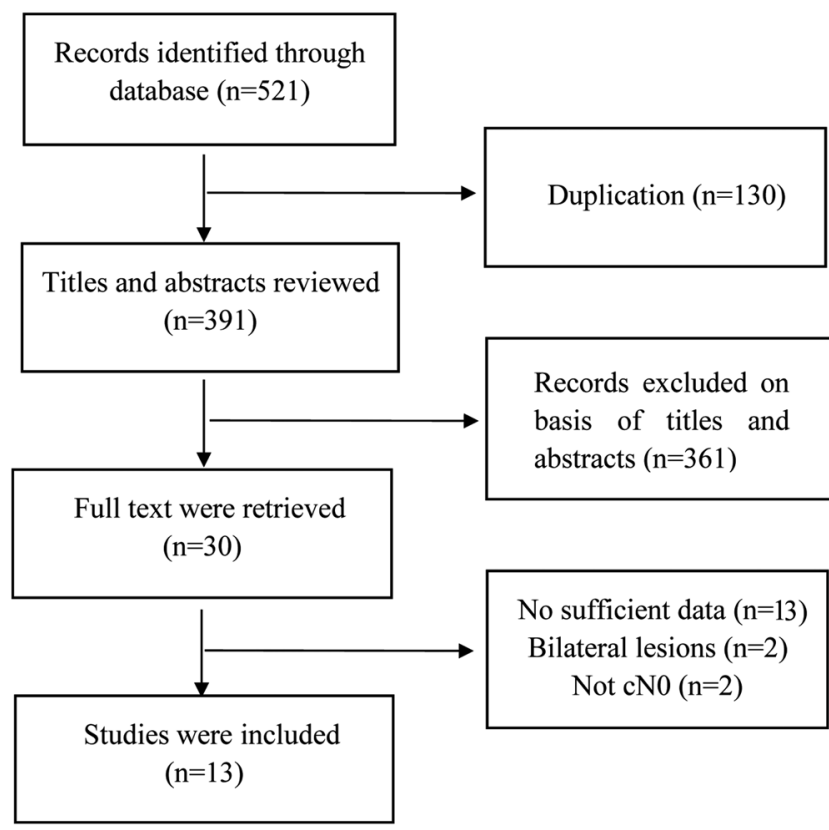

Figure 1

Flow chart of the study selection process.

\section{Capsular invasion}

The data from six included studies was assessed using a random-effects model $\left(P=0.04, I^{2}=56 \%\right)$. The results showed that CCLNM was not associated with capsular invasion in patients with cNO PTC $(\mathrm{OR}=1.57,95 \% \mathrm{CI}=$ 0.91-2.73, $P=0.11$ ) (Fig. 3B) (Supplementary Fig. 5).

\section{Extrathyroidal extension}

To analyze the association of extrathyroidal extension and CCLNM, 9 articles containing 1746 patients were included. This analysis used a fixed-effects model $\left(P=0.76, I^{2}=0 \%\right)$. The results showed that the proportion of CCLNM in patients with extrathyroidal extension was higher than that in patients without extrathyroidal extension ( $\mathrm{OR}=1.63 ; 95 \% \mathrm{CI}=1.17-2.28 ; P=0.004)$ (Fig. 3C) (Supplementary Fig. 6).

\section{Lymphovascular invasion}

Lymphovascular invasion was analyzed in eight articles using a fixed effects model $\left(P=0.64, I^{2}=0.0 \%\right)$. Lymphovascular invasion was associated with a 3.4fold higher risk of CCLNM in patients with cNO PTC $(\mathrm{OR}=4.27$, 95\% CI=2.47-7.37, $P<0.00001) \quad$ (Fig. 4A) (Supplementary Fig. 7).

\section{Hashimoto thyroiditis}

Five studies were included in the analysis of data involving Hashimoto's thyroiditis, which used a fixed-effects model $\left(I^{2}=0 \%, \quad P=0.46\right)$. Hashimoto thyroiditis was not associated with co-existing CCLNM $(\mathrm{OR}=1.05, \quad 95 \% \quad \mathrm{CI}=0.67-1.64, \quad P=0.82) \quad($ Fig. $4 \mathrm{~B})$ (Supplementary Fig. 8).

\section{Ipsilateral central lymph node metastasis}

Nine articles and 1711 patients were included to analyze the relationship of ipsilateral lymph node metastasis and CCLNM. Heterogeneity was assessed using a randomeffects model $\left(P=0.008, I^{2}=61 \%\right)$. The results showed that the proportion of CCLNM was $23.30 \%$ in patients with ipsilateral CLNM, which was significantly higher than that in patients without ipsilateral lymph node metastasis $(\mathrm{OR}=11.42$, 95\% CI $=5.25-24.86, P<0.00001)$ (Fig. 4C) (Supplementary Fig. 9).

\section{Discussion}

Most cases of PTC are not aggressive and have an optimistic prognosis; however, PTC shows a tendency for early spread to the central lymph node. The indications and prognostic effects of PCLND remain controversial. For differentiated thyroid cancer (DTC), the American Thyroid Association (ATA) guidelines recommend PCLND only for patients with stage T3-4 disease with cNO and all cN1b disease; however, a considerable number of surgeons, especially in China and Japan, still believe that it is valuable to perform ipsilateral central lymph node dissection while excising thyroid lesions (27). PCLND can help to make postoperative TNM staging and recurrence risk stratification more accurate, and aid the identification of patients that are suitable for RAI treatment $(11,12,13)$. For experienced surgeons, ipsilateral central lymph node dissection does not increase the incidence of surgical complications and operation time (14). CCLNM is not common compared with ipsilateral central lymph node metastasis; however, studies have reported that CCLNM occurs in $3.88-30.63 \%$ in patients with cN0 PTC (19, 20 ). The omission of lymph nodes is bound to increase the rate of reoperation and affect patient prognosis (28). However, it is worth noting that there is still no effective method to predict which patients have lymph node metastasis in the contralateral central lymph node. (c) 2020 The authors Published by Bioscientifica Ltd



This work is licensed under a Creative Commons Attribution 4.0 International License. ded from Bioscientifica.com at 04/26/2023 05:04:25AM 
A

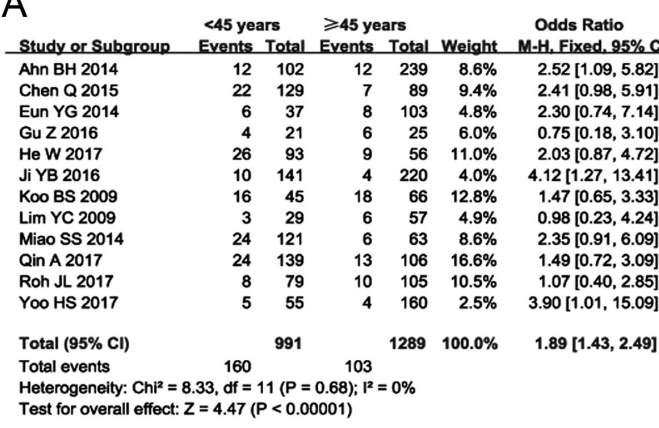

B

\begin{tabular}{|c|c|c|c|c|c|}
\hline Study or Subgroup & $\begin{array}{c}\text { male } \\
\text { Events }\end{array}$ & & $\begin{array}{l}\text { female } \\
\text { Events }\end{array}$ & & \\
\hline Ahn BH 2014 & 6 & 39 & 21 & 302 & $6.5 \%$ \\
\hline Chen Q 2015 & 10 & 48 & 19 & 170 & $10.5 \%$ \\
\hline Eun YG 2014 & 2 & 21 & 12 & 119 & $5.2 \%$ \\
\hline Gu Z 2016 & 2 & 6 & 8 & 40 & $2.2 \%$ \\
\hline He W 2017 & 10 & 40 & 25 & 109 & $16.0 \%$ \\
\hline Ji YB 2016 & 1 & 54 & 13 & 307 & $6.1 \%$ \\
\hline Koo BS 2009 & 7 & 16 & 27 & 95 & $7.0 \%$ \\
\hline Lim YC 2009 & 1 & 4 & 8 & 82 & $0.9 \%$ \\
\hline Miao SS 2014 & 7 & 44 & 23 & 140 & $14.7 \%$ \\
\hline Qin A 2017 & 13 & 60 & 24 & 185 & $14.6 \%$ \\
\hline Roh JL 2017 & 7 & 40 & 10 & 144 & $5.7 \%$ \\
\hline Yoo HS 2017 & 2 & 38 & 7 & 177 & $3.7 \%$ \\
\hline Zhang L 2016 & 9 & 34 & 15 & 135 & $7.0 \%$ \\
\hline Total $(95 \% \mathrm{Cl})$ & & 444 & & 2005 & $100.0 \%$ \\
\hline Total events & 77 & & 212 & & \\
\hline $\begin{array}{l}\text { Heterogeneity: }\left.\mathrm{Ch}\right|^{2}= \\
\text { Test for overall effect: }\end{array}$ & $\begin{array}{l}.13, \mathrm{df}= \\
=3.40\end{array}$ & $P=$ & $\begin{array}{l}0.77) ; 1^{2} \\
007)\end{array}$ & & \\
\hline
\end{tabular}

Odds Ratio H. Fixed, 95\% Cl $2.43[0.92,6.46]$ $2.09[0.90,4.87]$ $0.94[0.19,4.53]$ $2.00[0.31,12.92]$ $1.12[0.48,2.60]$ $0.43[0.05,3.33]$ $1.96[0.66,5.79]$ .08 $[0.29,33.24]$ $0.96[0.38,2.42]$ $1.86[0.88,3.92]$ $2.84[1.01,8.03]$ $1.35[0.27,6.76]$
$2.88[1.13,7.31]$

$1.67[1.24,2.24]$ Test for overall effect: $Z=3.40(P=0.0007)$

C

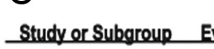
Chen Q 2015 Gu Z 2016 He W 2017 Ji YB 2016 Qin A 2017

Roh JL 2017 Zhang L 2016

Total $(95 \% \mathrm{Cl})$

Total events $\geq 1 \mathrm{~cm} \quad<1 \mathrm{~cm} \quad$ Odds Ratio Total Events Total Weight M-H. Fixed, 95\% $\begin{array}{llllll}15 & 83 & 14 & 135 & 22.1 \% & 1.91[0.87,4.19]\end{array}$ $\begin{array}{llllll}4 & 18 & 6 & 26 & 9.7 \% & 0.95[0.23,4.01]\end{array}$ $\begin{array}{llllll}24 & 92 & 11 & 57 & 25.5 \% & 1.48[0.66,3.30]\end{array}$ $\begin{array}{rrrrrr}11 & 139 & 3 & 222 & 5.4 \% & 6.27[1.72,22.91]\end{array}$ $\begin{array}{llllll}26 & 116 & 11 & 129 & 20.5 \% & 3.10[1.45,6.60]\end{array}$ $\begin{array}{llllll}16 & 99 & 2 & 85 & 4.6 \% & 8.00[1.78,35.89]\end{array}$ $\begin{array}{llllrr}12 & 46 & 12 & 123 & 12.2 \% & 3.26[1.34,7.93]\end{array}$ Heterogeneity: $\mathrm{Ch}^{2}=8.78, \mathrm{df}=6(\mathrm{P}=0.19) ; \mathrm{l}^{2}=32 \%$ Test for overall effect: $Z=5.38(P<0.00001)$

$777 \quad 100.0 \% \quad 2.63[1.85,3.74]$

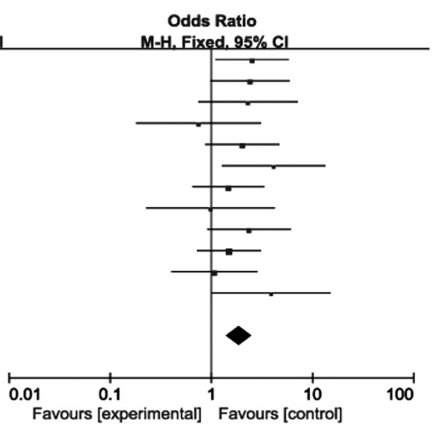

Odds Ratio

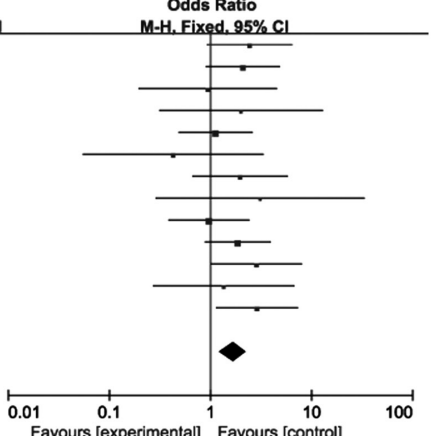

Favours [experimental] Favours [control]

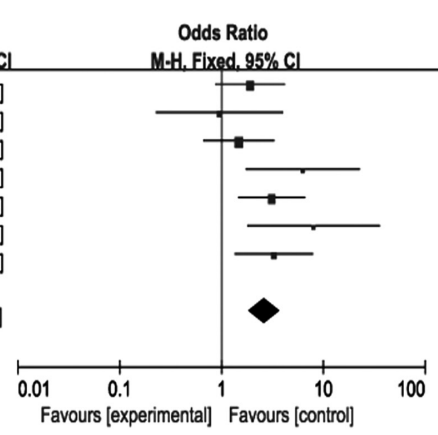

Figure 2

Forest plots of the association between age, sex, size, and CCLNM in cNO PTC. (A) Age; (B) sex; (C) size.
The sensitivities of US and contrast enhanced CT are low. In addition, fine-needle aspiration cytology is associated with false negative rates of $6-8 \%$, which can be up to $20 \%$ in non-diagnostic specimens (29). Thus, it is important to use clinical pathological data to predict which patients could have CCLNM. The outcome of this study is based on soft data (e.g., the presence or absence of metastases in the contralateral central lymph nodes), but not on the recurrence rate or survival.

Age is an important prognostic factor for DTC, and the prognosis of patients with DTC worsens with increasing age (30). However, many studies have reported that young age is a risk factor for lymph node metastasis (31, $32)$. In the present meta-analysis, age less than 45 years was identified as an important risk factor for CCLNM. Therefore, contralateral central lymph node dissection should be performed in patients younger than 45 years old because of their probability of good prognosis.
Thyroid cancer is a female-dominant sex-dimorphic cancer and the incidence of PTC among woman is nearly three-times higher than that in men (33). However, male patients are also more likely to have unhealthy lifestyles and harmful environmental factors, for example, drinking alcohol and smoking (34). Men's poorer prognosis compared with that of women has been reported by several studies $(35,36)$. The meta-analysis indicated that in patients with cNO PTC, male sex is a significant risk factor for CCLNM.

The National Thyroid Cancer Treatment Cooperative Study (NTCTCS), the American Joint Committee on Cancer (AJCC), and MACIS (metastasis, age, completeness of resection, invasion, size) frequently use tumor size in their staging systems (37). Risk stratification has used $1 \mathrm{~cm}$ as most common cut-off and is accepted as a risk factor for CLNM $(6,38)$. Larger tumors are more likely to be aggressive, undergo lymph node metastasis, and result

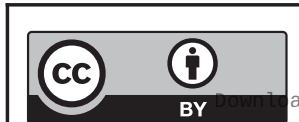

This work is licensed under a Creative Commons Attribution 4.0 International License. 
A

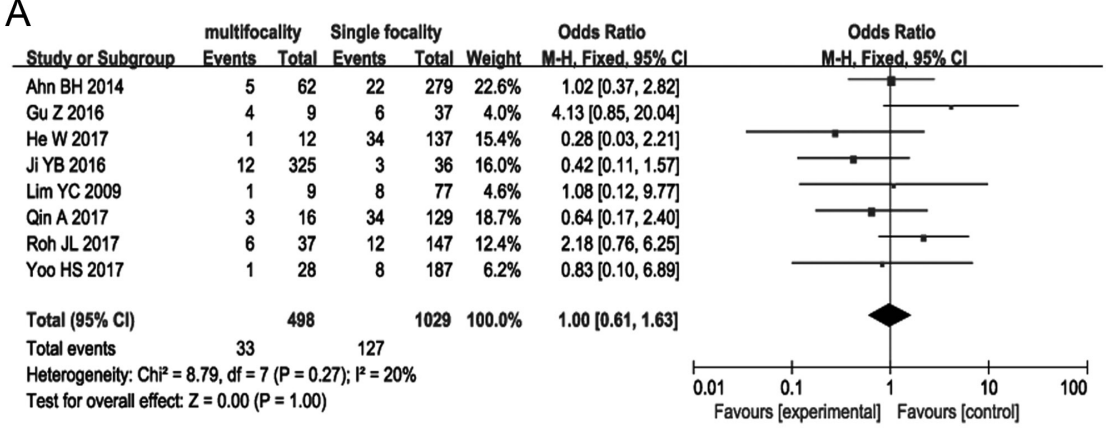

B

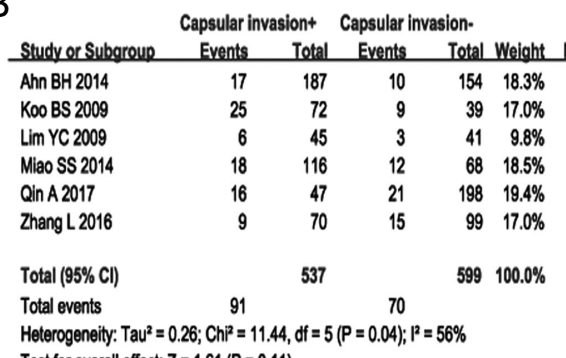

Test for overall effect: $Z=1.61(P=0.11)$
Odds Ratio

H. Random, $95 \% \mathrm{Cl}$

$1.44[0.64,3.24]$
$1.77[0.73,4.31]$

$1.95[0.45,8.36]$

$0.86[0.38,1.91]$

$4.35[2.05,9.25]$

$0.83[0.34,2.01]$

$1.57[0.91,2.73]$

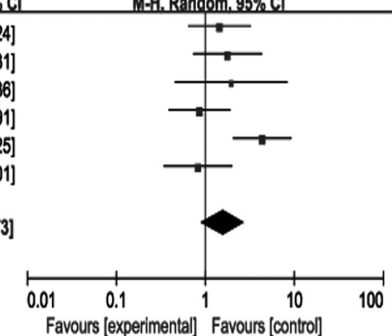

Odds Ratio M-H. Random. $95 \% \mathrm{C}$

C

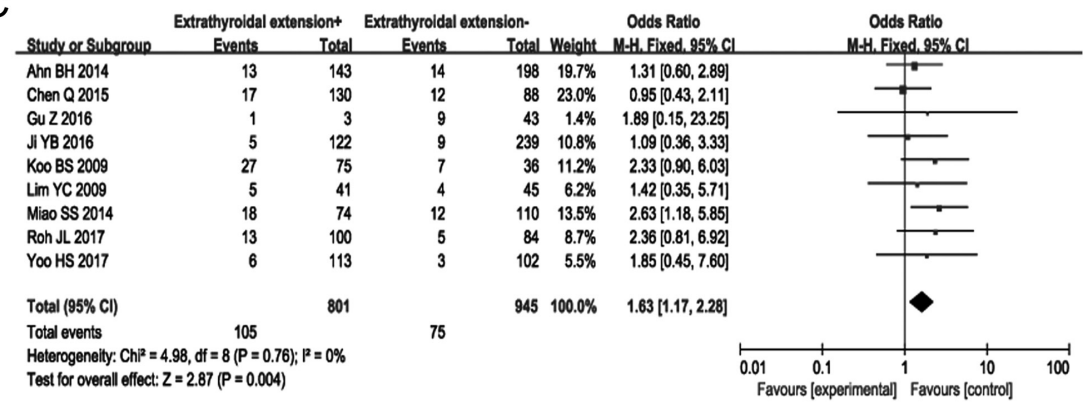

Figure 3

Forest plots of the association between multifocality, capsular invasion extrathyroidal extension and CCLNM in CNO PTC.

(A) Multifocality; (B) capsular invasion; (C) extrathyroidal extension. in poor prognosis. In the present meta-analysis, patients with cNO PTC with a tumor size $\geq 1 \mathrm{~cm}$ had a 2.4-fold increased risk of CCLNM.

It is a matter of debate as to whether multifocality is associated with CCLNM in patients with cNO PTC. Multifocal PTC is believed to be more aggressive compared with unifocal PTC and is an independent risk factor for PTC recurrence after total thyroidectomy (39). However, a propensity score-matching analysis indicated that multifocality is not an independent prognostic factor in PTC (40). Similarly, the results of the present study indicated that multifocality is not a risk factor for CCLNM.

Whether patients with Hashimoto thyroiditis (HT) are predisposed to develop thyroid nodules and thyroid cancer is unclear. The coexistence of HT has been suggested as not associated with CCLNM in patients with PTC or PTMC (41). A previous meta-analysis revealed that patients with PTC and coexisting HT exhibited less aggressive clinicopathological characteristics, such as lower rates of lymph node metastasis and extrathyroidal extension, and experienced longer recurrence-free survival compared with patients with PTC without HT (42). The results of the present meta-analysis suggested no association between HT and CCLNM in patients with cNO PTC. The discrepancies between the present findings and those of previous studies might reflect different selection criteria and study designs.

The course of PTC is slow and long. The tumor may break through the glandular capsular and invade the capsular or surrounding muscles and blood vessels, and the recurrent laryngeal nerve. Extrathyroid extension and lymphovascular invasion are believed to have an marked effect on lymph node metastasis and poor prognosis (43). However, whether capsular invasion is a prognostic factor in PTC remains controversial. Studies reported that capsular invasion does not seem to cause death but is an independent risk factor for regional recurrence (44, 45). The results of the present meta-analysis showed https://ec.bioscientifica.com

https://doi.org/10.1530/EC-20-0058 (c) 2020 The authors Published by Bioscientifica Ltd

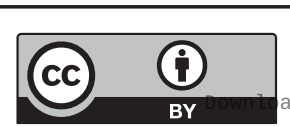

This work is licensed under a Creative Commons Attribution 4.0 International License. 
A

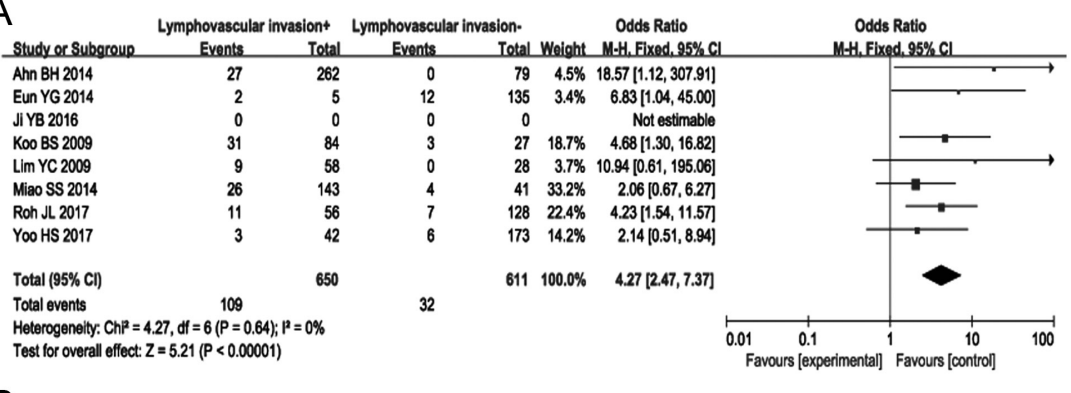

B

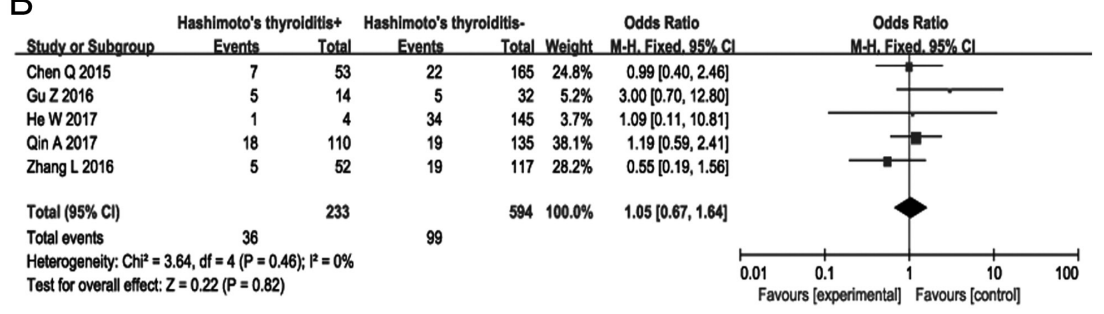

C

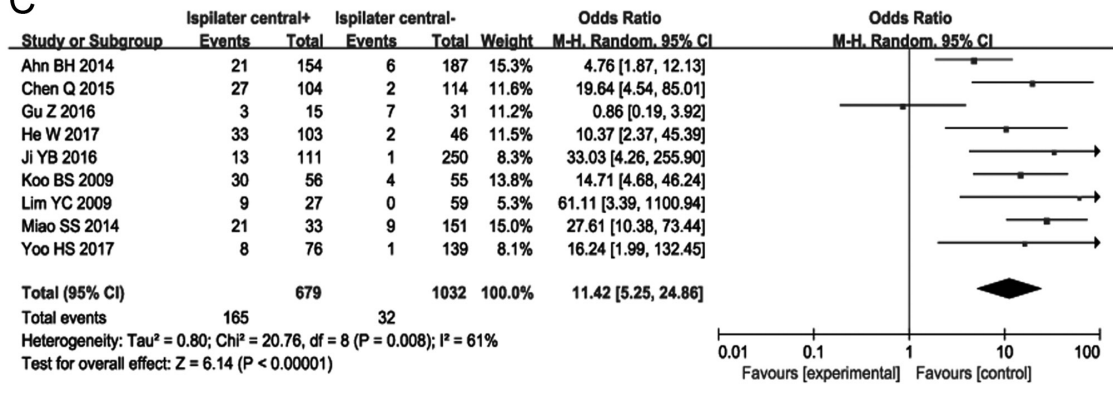

\section{Figure 4}

Forest plots of the association between lymphovascular invasion, Hashimoto thyroiditis, ipsilateral central lymph node metastasis and CCLNM in CNO PTC. (A) Lymphovascular invasion; (B) Hashimoto thyroiditis; (C) ipsilateral central lymph node metastasis. that CCLNM was more likely to occur in patients with extrathyroid extension and lymphovascular invasion. However, capsular invasion was not a risk factor associated with CCLNM.

In the present study, although occult CCLNM was rare, it was associated with the occurrence of ipsilateral central compartment metastasis. The presence of ipsilateral central compartment metastasis exhibited a 7.83-fold increased risk of CCLNM compared with patients without this type of metastasis. Thus, for this subset of patients, ipsilateral PCLND could represent an appropriate prophylactic procedure. If frozen biopsy shows metastasis to the ipsilateral central lymph node, CCLNM dissection can be performed.

The present study has some limitations. First, the studies that we included were not randomized casecontrol trials. Second, despite lymph node metastasis being closely associated with the tumor location in the thyroid gland, no tumor was analyzed for its location in this meta-analysis. Third, the majority of the patients analyzed from the included studies were from Asia. Fourth, prospective and retrospective studies were mixed in this study. Five, we were limited to the original data from the included studies; therefore, we could not obtain enough data to perform multivariate analysis.

In summary, the meta-analysis identified age, gender, tumor size, extrathyroid expansion, and lymphatic invasion as important risk factors for CCLNM in patients with cNO PTC. In patients with cNO PTC, CCLNM did nor correlate with multifocality, capsule invasion, or Hashimoto thyroiditis.

\section{Supplementary materials}

This is linked to the online version of the paper at https://doi.org/10.1530/ EC-20-0058.

Declaration of interest

The authors declare that there is no conflict of interest that could be perceived as prejudicing the impartiality of the research reported.

\section{Funding}

This work was supported by the Liaoning BaiQianWan Talents Program (No. 2014921033), Natural Science Foundation of Liaoning Province (No. 20180530090), the National Natural Science Foundation of China (No. 81902726), and the Project funded by China Postdoctoral Science Foundation (No. 2018M641739). https://ec.bioscientifica.com https://doi.org/10.1530/EC-20-0058 (c) 2020 The authors Published by Bioscientifica Ltd

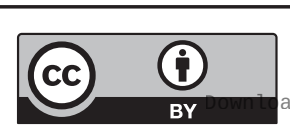

This work is licensed under a Creative Commons Attribution 4.0 International License. 


\section{Data availability statement}

The data sets used and/or analyzed during the current study are available from the corresponding author on reasonable request.

\section{References}

1 Hundahl SA, Fleming ID, Fremgen AM \& Menck HR. A National Cancer Data Base report on 53,856 cases of thyroid carcinoma treated in the U.S. 1985-1995. Cancer 199883 2638-2648. (https:// doi.org/10.1002/(sici)1097-0142(19981215)83:123.0.co;2-1)

2 Lundgren CI, Hall P, Dickman PW \& Zedenius J. Clinically significant prognostic factors for differentiated thyroid carcinoma: a populationbased, nested case-control study. Cancer 2006106 524-531. (https:// doi.org/10.1002/cncr.21653)

3 Cabanillas ME, McFadden DG \& Durante C. Thyroid cancer. Lancet 2016388 2783-2795. (https://doi.org/10.1016/S01406736(16)30172-6)

4 Cooper DS, Doherty GM, Haugen BR, Kloos RT, Lee SL, Mandel SJ, Mazzaferri EL, Mciver B, Sherman SI, Tuttle RM, et al. Management guidelines for patients with thyroid nodules and differentiated thyroid cancer. Thyroid 200616 109-142. (https://doi.org/10.1089/ thy.2006.16.109)

5 Shaha AR. Management of the neck in thyroid cancer. Otolaryngologic Clinics of North America 199831 823-831. (https://doi.org/10.1016/ S0030-6665(05)70090-6)

6 Roh JL, Kim JM \& Park CI. Central lymph node metastasis of unilateral papillary thyroid carcinoma: patterns and factors predictive of nodal metastasis, morbidity, and recurrence. Annals of Surgical Oncology 201118 2245-2250. (https://doi.org/10.1245/ s10434-011-1600-z)

7 White ML, Gauger PG \& Doherty GM. Central lymph node dissection in differentiated thyroid cancer. World Journal of Surgery 200731 895-904. (https://doi.org/10.1007/s00268-006-0907-6)

8 Amit M, Tam S, Boonsripitayanon M, Cabanillas ME, Busaidy NL, Grubbs EG, Lai SY, Gross ND, Sturgis EM \& Zafereo ME. Association of lymph node density with survival of patients with papillary thyroid cancer. JAMA Otolaryngology: Head and Neck Surgery 2018144 108-114. (https://doi.org/10.1001/jamaoto.2017.2416)

9 Nixon IJ, Wang LY, Ganly I, Patel SG, Morris LG, Migliacci JC, Tuttle RM, Shah JP \& Shaha AR. Outcomes for patients with papillary thyroid cancer who do not undergo prophylactic central neck dissection. British Journal of Surgery 2016103 218-225. (https://doi. org/10.1002/bjs.10036)

10 Nixon IJ, Ganly I, Patel SG, Morris LG, Palmer FL, Thomas D, Tuttle RM, Shah JP \& Shaha AR. Observation of clinically negative central compartment lymph nodes in papillary thyroid carcinoma. Surgery 2013154 1166-1172; discussion 1172. (https://doi. org/10.1016/j.surg.2013.04.035)

11 Moo TA, McGill J, Allendorf J, Lee J, Fahey TR \& Zarnegar R. Impact of prophylactic central neck lymph node dissection on early recurrence in papillary thyroid carcinoma. World Journal of Surgery 201034 1187-1191. (https://doi.org/10.1007/s00268-010-0418-3)

12 Mazzaferri EL, Doherty GM \& Steward DL. The pros and cons of prophylactic central compartment lymph node dissection for papillary thyroid carcinoma. Thyroid 200919 683-689. (https://doi. org/10.1089/thy.2009.1578)

13 Lan X, Sun W, Zhang H, Dong W, Wang Z \& Zhang T. A metaanalysis of central lymph node metastasis for predicting lateral involvement in papillary thyroid carcinoma. Otolaryngology: Head and Neck Surgery 2015153 731-738. (https://doi. org/10.1177/0194599815601412)

14 Barczynski M, Konturek A, Stopa M \& Nowak W. Prophylactic central neck dissection for papillary thyroid cancer. British Journal of Surgery 2013100 410-418. (https://doi.org/10.1002/bjs.8985)
15 Popadich A, Levin O, Lee JC, Smooke-Praw S, Ro K, Fazel M, Arora A, Tolley NS, Palazzo F, Learoyd DL, et al. A multicenter cohort study of total thyroidectomy and routine central lymph node dissection for cN0 papillary thyroid cancer. Surgery 2011150 1048-1057. (https:// doi.org/10.1016/j.surg.2011.09.003)

16 Sywak M, Cornford L, Roach P, Stalberg P, Sidhu S \& Delbridge L. Routine ipsilateral level VI lymphadenectomy reduces postoperative thyroglobulin levels in papillary thyroid cancer. Surgery 2006 140 1000-1005; discussion 1005. (https://doi.org/10.1016/j. surg.2006.08.001)

17 Machens A, Hinze R, Thomusch O \& Dralle H. Pattern of nodal metastasis for primary and reoperative thyroid cancer. World Journal of Surgery 200226 22-28. (https://doi.org/10.1007/s00268-0010176-3)

18 Onoda N, Ishikawa T, Kawajiri H, Takashima T \& Hirakawa K. Pattern of initial metastasis in the cervical lymph node from papillary thyroid carcinoma. Surgery Today 201343 178-184. (https://doi. org/10.1007/s00595-012-0228-3)

19 Ji YB, Yoo HS, Song CM, Park CW, Lee CB \& Tae K. Predictive factors and pattern of central lymph node metastasis in unilateral papillary thyroid carcinoma. Auris, Nasus, Larynx 201643 79-83. (https://doi. org/10.1016/j.anl.2015.09.005)

20 Koo BS, Choi EC, Yoon YH, Kim DH, Kim EH \& Lim YC. Predictive factors for ipsilateral or contralateral central lymph node metastasis in unilateral papillary thyroid carcinoma. Annals of Surgery 2009249 840-844. (https://doi.org/10.1097/SLA.0b013e3181a40919)

21 So YK, Seo MY \& Son YI. Prophylactic central lymph node dissection for clinically node-negative papillary thyroid microcarcinoma: influence on serum thyroglobulin level, recurrence rate, and postoperative complications. Surgery 2012151 192-198. (https://doi. org/10.1016/j.surg.2011.02.004)

22 Giordano D, Valcavi R, Thompson GB, Pedroni C, Renna L, Gradoni P \& Barbieri V. Complications of central neck dissection in patients with papillary thyroid carcinoma: results of a study on 1087 patients and review of the literature. Thyroid 201222 911-917. (https://doi.org/10.1089/thy.2012.0011)

23 Kim SK, Woo JW, Park I, Lee JH, Choe JH, Kim JH \& Kim JS. Computed tomography-detected central lymph node metastasis in ultrasonography node-negative papillary thyroid carcinoma: is it really significant? Annals of Surgical Oncology 201724 442-449. (https://doi.org/10.1245/s10434-016-5552-1)

24 Kim E, Park JS, Son KR, Kim JH, Jeon SJ \& Na DG. Preoperative diagnosis of cervical metastatic lymph nodes in papillary thyroid carcinoma: comparison of ultrasound, computed tomography, and combined ultrasound with computed tomography. Thyroid $2008 \mathbf{1 8}$ 411-418. (https://doi.org/10.1089/thy.2007.0269)

25 Khokhar MT, Day KM, Sangal RB, Ahmedli NN, Pisharodi LR, Beland MD \& Monchik JM. Preoperative high-resolution ultrasound for the assessment of malignant central compartment lymph nodes in papillary thyroid cancer. Thyroid 201525 1351-1354. (https://doi. org/10.1089/thy.2015.0176)

26 Moher D, Liberati A, Tetzlaff J, Altman DG \& PRISMA Group. Preferred reporting items for systematic reviews and meta-analyses: the PRISMA statement. International Journal of Surgery 20108 336-341. (https://doi.org/10.1016/j.ijsu.2010.02.007)

27 Haugen BR, Alexander EK, Bible KC, Doherty GM, Mandel SJ, Nikiforov YE, Pacini F, Randolph GW, Sawka AM, Schlumberger M, et al. 2015 American Thyroid Association management guidelines for adult patients with thyroid nodules and differentiated thyroid cancer: the American Thyroid Association Guidelines Task Force on thyroid nodules and differentiated thyroid cancer. Thyroid 201626 1-133. (https://doi.org/10.1089/thy.2015.0020)

28 Zhao W, You L, Hou X, Chen S, Ren X, Chen G \& Zhao Y. The effect of prophylactic central neck dissection on locoregional recurrence in papillary thyroid cancer after total thyroidectomy: a systematic review and meta-analysis: pCND for the locoregional recurrence

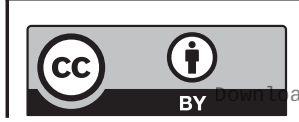

This work is licensed under a Creative Commons Attribution 4.0 International License. ded from Bioscientifica.com at 04/26/2023 05:04:25AM 
of papillary thyroid cancer. Annals of Surgical Oncology 201724 2189-2198. (https://doi.org/10.1245/s10434-016-5691-4)

29 Alexander EK, Heering JP, Benson CB, Frates MC, Doubilet PM, Cibas ES \& Marqusee E. Assessment of nondiagnostic ultrasoundguided fine needle aspirations of thyroid nodules. Journal of Clinical Endocrinology and Metabolism 200287 4924-4927. (https://doi. org/10.1210/jc.2002-020865)

30 Kim M, Kim YN, Kim WG, Park S, Kwon H, Jeon MJ, Ahn HS, Jung SH, Kim SW, Kim WB, et al. Optimal cut-off age in the TNM staging system of differentiated thyroid cancer: is 55 years better than 45 years? Clinical Endocrinology 201786 438-443. (https://doi. org/10.1111/cen.13254)

31 Obregon-Guerrero G, Martinez-Ordaz JL, Pena-Garcia JF, RamirezMartinez ME, Perez-Alvarez C \& Hernandez-Avendano V. Factors associated with malignancy in patients with thyroid nodules. Cirugia y Cirujanos 201078 479-484.

32 Raza SN, Shah MD, Palme CE, Hall FT, Eski S \& Freeman JL. Risk factors for well-differentiated thyroid carcinoma in patients with thyroid nodular disease. Otolaryngology: Head and Neck Surgery 2008 139 21-26. (https://doi.org/10.1016/j.otohns.2007.10.021)

33 Libutti SK. Understanding the role of gender in the incidence of thyroid cancer. Cancer Journal 200511 104-105. (https://doi. org/10.1097/00130404-200503000-00003)

34 Hegedus L. Clinical practice. The thyroid nodule. New England Journal of Medicine 2004351 1764-1771. (https://doi.org/10.1056/ NEJMcp031436)

35 Besic N, Pilko G, Petric R, Hocevar M \& Zgajnar J. Papillary thyroid microcarcinoma: prognostic factors and treatment. Journal of Surgical Oncology 200897 221-225. (https://doi.org/10.1002/jso.20935)

36 Shaha AR, Shah JP \& Loree TR. Risk group stratification and prognostic factors in papillary carcinoma of thyroid. Annals of Surgical Oncology 19963 534-538. (https://doi.org/10.1007/bf02306085)

37 Lang BH, Lo CY, Chan WF, Lam KY \& Wan KY. Staging systems for papillary thyroid carcinoma: a review and comparison. Annals of Surgery 2007245 366-378. (https://doi.org/10.1097/01. sla.0000250445.92336.2a)

38 Ahn BH, Kim JR, Jeong HC, Lee JS, Chang ES \& Kim YH. Predictive factors of central lymph node metastasis in papillary thyroid carcinoma. Annals of Surgical Treatment and Research 201588 63-68. (https://doi.org/10.4174/astr.2015.88.2.63)

39 Choi WR, Roh JL, Gong G, Cho KJ, Choi SH, Nam SY \& Kim SY. Multifocality of papillary thyroid carcinoma as a risk factor for disease recurrence. Oral Oncology 201994 106-110. (https://doi. org/10.1016/j.oraloncology.2019.05.023)

40 Geron Y, Benbassat C, Shteinshneider M, Or K, Markus E, Hirsch D, Levy S, Ziv-Baran T \& Muallem-Kalmovich L. Multifocality is not an independent prognostic factor in papillary thyroid cancer: a propensity score-matching analysis. Thyroid 201929 513-522. (https://doi.org/10.1089/thy.2018.0547)

41 Kim EY, Kim WG, Kim WB, Kim TY, Kim JM, Ryu JS, Hong SJ, Gong G \& Shong YK. Coexistence of chronic lymphocytic thyroiditis is associated with lower recurrence rates in patients with papillary thyroid carcinoma. Clinical Endocrinology 200971 581-586. (https:// doi.org/10.1111/j.1365-2265.2009.03537.x)

42 Moon S, Chung HS, Yu JM, Yoo HJ, Park JH, Kim DS \& Park YJ. Associations between Hashimoto thyroiditis and clinical outcomes of papillary thyroid cancer: a meta-analysis of observational studies.
Endocrinology and Metabolism 201833 473-484. (https://doi. org/10.3803/EnM.2018.33.4.473)

43 Lee YK, Kim D, Shin DY, Lee CR, Lee EJ, Kang SW, Lee J, Jeong JJ, Nam KH, Chung WY, et al. The prognosis of papillary thyroid cancer with initial distant metastasis is strongly associated with extensive extrathyroidal extension: a retrospective cohort study. Annals of Surgical Oncology 201926 2200-2209. (https://doi.org/10.1245/ s10434-019-07314-x)

44 Ge MH, Cao J, Wang JY, Huang YQ, Lan XB, Yu B, Wen QL \& Cai XJ. Nomograms predicting disease-specific regional recurrence and distant recurrence of papillary thyroid carcinoma following partial or total thyroidectomy. Medicine 201796 e7575. (https://doi. org/10.1097/MD.0000000000007575)

45 Xu B, Ibrahimpasic T, Wang L, Sabra MM, Migliacci JC, Tuttle RM, Ganly I \& Ghossein R. Clinicopathologic features of fatal nonanaplastic follicular cell-derived thyroid carcinomas. Thyroid 201626 1588-1597. (https://doi.org/10.1089/thy.2016.0247)

46 Chen Q, Zou XH, Wei T, Huang QS, Sun YH \& Zhu JQ. Prediction of ipsilateral and contralateral central lymph node metastasis in unilateral papillary thyroid carcinoma: a retrospective study. Gland Surgery 20154 288-294. (https://doi.org/10.3978/j.issn.2227684X.2015.05.06)

47 Eun YG, Lee YC \& Kwon KH. Predictive factors of contralateral paratracheal lymph node metastasis in papillary thyroid cancer: prospective multicenter study. Otolaryngology: Head and Neck Surgery 2014150 210-215. (https://doi.org/10.1177/0194599813514726)

48 Lim YC, Choi EC, Yoon YH, Kim EH \& Koo BS. Central lymph node metastases in unilateral papillary thyroid microcarcinoma. British Journal of Surgery 200996 253-257. (https://doi.org/10.1002/ bjs.6484)

49 Miao S, Mao X, Pei R, Xiang C, Lv Y, Shi Q, Zhao S, Sun J \& Jia S. Predictive factors for different subgroups of central lymph node metastasis in unilateral papillary thyroid carcinoma. Journal for OtoRhino-Laryngology and its Related Specialties 201375 265-273. (https:// doi.org/10.1159/000354267)

$50 \mathrm{Gu}$ Z, Shan C, Liu J, Feng Y, Qiu M \& Xu X. Patterns and predictive factor of central lymph node metastasis in cNO papillary thyroid cancer. Academic Journal of Second Military Medical University 201637 544-547.

51 He W, Su X ,Wu K, Zhou J, Hu D, Cao Y, Mao Y \& Ren H. Factors related to contralateral central lymph node metastasis in clinically node-nega-tive papillary thyroid carcinoma. Chinese Journal of Clinical Oncology 201744 41-45. (https://doi.org/10.3969/j. issn.1000-8179.2017.01.193)

52 Qin A, Liu X, Zhang G \& Chu C. Prophylactic central lymph node dissection for patients of cN0 thyroid papillary carcinoma. Chinese Journal of General Surgery 201732 202-206. (https://doi.org/10.3760/ cma.j.issn.1007-631X.2017.03.005)

53 Yoo HS, Shin MC, Ji YB, Song CM, Lee SH \& Tae K. Optimal extent of prophylactic central neck dissection for papillary thyroid carcinoma: comparison of unilateral versus bilateral central neck dissection. Asian Journal of Surgery 201841 363-369. (https://doi.org/10.1016/j. asjsur.2017.03.002)

54 Zhang L, Yang J, Sun Q, Liu Y, Chen G, Chen S,Gao W \& Li X. Risk factors for high-volume lymph node metastases in cNO papillary thyroid microcar-cinoma. Chinese Journal of Clinical Oncology 201744 805-809. (https://doi.org/10.3969/j.issn.1000-8179.2017.16.352)

Received in final form 2 April 2020

Accepted 8 April 2020

Accepted Manuscript published online 9 April 2020 https://ec.bioscientifica.com https://doi.org/10.1530/EC-20-0058 (c) 2020 The authors Published by Bioscientifica Ltd



This work is licensed under a Creative Commons Attribution 4.0 International License. ded from Bioscientifica.com at 04/26/2023 05:04:25AM 